\title{
Public beliefs about the causes of obesity and attitudes towards policy initiatives in Great Britain
}

\author{
Rebecca J Beeken* and Jane Wardle \\ Health Behaviour Research Centre, Department of Epidemiology \& Public Health, University College London, \\ Gower Street, London WC1E 6BT, UK
}

Submitted 28 January 2013: Final revision received 10 May 2013: Accepted 5 June 2013: First published online 18 July 2013

\begin{abstract}
Objective: To assess attributions for overweight and the level of support for policy initiatives in Great Britain.

Design: Cross-sectional. Respondents indicated their agreement (5-point scales: strongly disagree to strongly agree) to three potential causes of overweight (environment, genes, willpower) and five policies (free weight-loss treatment, taxing unhealthy foods, healthy lifestyle campaigns, food labelling, advertising restrictions).

Setting: Data were collected as part of a computer-assisted, face-to-face Omnibus survey of adults (aged $>15$ years) from across Great Britain in April 2012 carried out by a market research company.

Subjects: A population-representative sample of British adults ( $n$ 1986).

Results: More people attributed overweight to the food environment (61\%) and lack of willpower (57\%) than to genes (45\%). Policy support was highest for healthy lifestyle campaigns (71\%) and food labelling (66\%), and lowest for taxing unhealthy foods (32\%). Food environment attributions were associated with higher support for all policies $(P<0 \cdot 001)$. Genetic attributions were associated with higher support for free weight-loss treatments and healthy lifestyle campaigns $(P<0 \cdot 001)$, but not other policies. Attributions to lack of willpower were not associated differentially with support for any policies $(P>0 \cdot 01)$.

Conclusions: Belief that overweight is caused by the food environment or genes both seen as outside individual control - was associated with greater support for government policies to prevent and treat obesity. Improving awareness of the multiple causes of obesity could facilitate acceptance of policy action to reduce obesity prevalence.
\end{abstract}

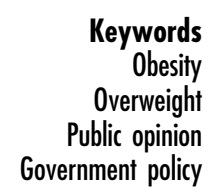

The prevalence of obesity in the UK has increased dramatically in recent years, rising in England from 15\% to $25 \%$ between 1993 and $2011^{(1)}$, with rates expected to continue to go up ${ }^{(2)}$. The health consequences of obesity place an immense burden on public health services ${ }^{(3,4)}$ and there are also significant economic costs associated with obesity $^{(5,6)}$. Consequently, the government is increasingly called upon to intervene and tackle the problem ${ }^{(7,8)}$. However, there is public debate about the rights and wrongs of government intervention in preventing and treating obesity, with the issue that obesity is either selfinflicted or at some level a personal choice being adduced as an argument against expenditure from the public purse.

In the recent white paper Healthy Lives, Healthy People ${ }^{(9)}$, the British government presented plans to 'nudge' people into making healthier choices while avoiding 'nannying'. This approach was widely criticized as being too soft and underplaying environmental influences by the health community $^{(10,11)}$. However, a recent survey of general public attitudes across twenty-four countries commissioned by the UK government indicated that there was limited public support for more coercive policies ${ }^{(12)}$. The majority of respondents favoured approaches such as the provision of information on healthy choices, and just over half (53\%) agreed that the government should 'not get involved in what people choose to eat'. Population-based surveys in Denmark, Germany, Australia and the USA have also shown less public support for regulation and taxation $^{(13-16)}$.

One explanation for the low support for more intensive government intervention may be the perceived causes of overweight and obesity $^{(17)}$. The pervasive stereotypes and stigma surrounding obesity may mean that it is still seen as 'the person's own fault', leading to objections against public expenditure because the condition is perceived to be 'self-inflicted'. Although research from the USA ${ }^{(18)}$ and 
Ireland $^{(19)}$ indicates that representations of obesity in the media are becoming more balanced with respect to attributing responsibility between the individual and the environment, portrayal of genetic attributions is still low ${ }^{(19)}$ and in general weight stigma in health-related media is high $^{(20,21)}$. Studies of public perceptions suggest that most people attribute overweight and obesity to individual behavioural choices as opposed to factors over which the individual may have limited control, such as the environment or genetics ${ }^{(13,15,17,22,23)}$

There is evidence that attributions to factors outside individual control are associated with greater support for obesity policies, while stigmatizing attitudes predict lower support $^{(13-15,17,22,24)}$. However, to date only two studies have investigated attributions and attitudes in the UK, one of which specifically focused on the views of university students ${ }^{(25)}$. A survey of the general public ${ }^{(22)}$ was carried out in 2007 with 500 adults. It found that genes were considered to be the least important determinant of overweight, while agreement was highest for attributions linked with personal responsibility, although there was also support for the role of the environment in causing overweight. Attributions were linked to support for various policies; for example, attributing overweight to the food environment predicted greater support for all policies. However, the policies included in the survey were mainly child-focused or concerned with the protection of rights of overweight/obese people. Both that survey and the survey of university students were completed before the publication of the UK government strategy document ${ }^{(9)}$.

We therefore carried out a larger-scale, populationbased survey of attitudes towards a broader range of obesity policies. This survey was done after publication of Healthy Lives, Healthy People, which puts the responsibility for achieving a healthy weight very much on the individual and so may have reduced support for public policy initiatives, but also followed many years of publicity about 'obesity genes' that could have increased public sympathy. We assessed both attributions for overweight and the level of support for policy initiatives. We hypothesized that environmental or genetic causal attributions for obesity would be associated with higher support for policy initiatives, while attributions to individual lack of willpower would be associated with lower support.

\section{Methods}

\section{Study population}

Data were collected from a representative sample of 1986 British adults (932 men, 1054 women) as part of a homebased, computer-assisted, face-to-face Omnibus survey of 2000 adults (aged $>15$ years) from across Great Britain in April 2012 carried out by a market research company (TNS). The omnibus survey included questions from a range of contributors on a variety of non-health-related issues. TNS employs a random location methodology using 2001 Census small-area statistics and the postcode address file, stratified by Government Office Region and social grade, to select sample points. At each location, quotas were set for age, gender, children in the home and working status to ensure a balanced sample of adults within effective contacted addresses. Interviewers are instructed to leave three doors between each successful interview.

The study was conducted according to the guidelines laid down in the Declaration of Helsinki and was exempt from ethical approval under the guidelines of the University College London Research Ethics Committee which state that approval is not needed for studies involving the use of ... survey procedures ... unless information obtained is recorded in such a manner that human participants can be identified'. The survey was anonymous. TNS Research International abides by the Market Research Society Code of Conduct and data protection legislation.

\section{Measures}

\section{Demographics}

Demographic variables included in the present analyses were age, sex and socio-economic status (SES). SES was determined using the social grade classification created by the National Readership Survey ${ }^{(26)}$, which classifies people into A (higher managerial or professional occupations), B (intermediate managerial or professional occupations), C1 (supervisory or junior managerial occupations), C2 (skilled manual workers), D (semi-skilled and unskilled manual workers) and E (state pensioners or lowest grade workers). We combined the A and B categories to equalize group sizes, as only fifty-two people $(2 \cdot 6 \%)$ were classified as higher managerial or professional.

\section{Perceived weight status}

Respondents were asked to describe their own body size from the following list: 'very underweight', 'underweight', 'about right', 'overweight', 'very overweight' and 'obese'. Only three people described themselves as 'very underweight', so this category was combined with 'underweight'. Only thirty-two people (1.6\%) described themselves as 'obese', so this category was combined with 'very overweight'.

\section{Attributions for overweight and attitudes towards government obesity policies}

Single-item measures on attributions for overweight were developed based on questions used in previous studies $^{(15,22,25)}$. The 2007 survey used the term 'overweight' rather than 'obesity' due to concerns about the public's familiarity with the medical definition of obesity. While public awareness of the meaning of obesity is likely to have increased in the last 5 years, to enable us to compare our results with the 2007 findings, we also used 
the term 'overweight'. Respondents were asked to indicate their agreement to three statements on potential causes of overweight ('People are overweight because ... they inherit genes that cause weight gain/they lack willpower/there are so many unhealthy foods around') chosen to reflect genetic, individual and environment attributions for overweight. Respondents were also asked how much they agreed with the more general statement 'Being overweight is mainly the person's own fault'.

Respondents were asked to indicate their agreement with five statements on specific obesity policies, based on questions used in a previous study ${ }^{(25)}$, and chosen to reflect the issues that were felt to be topical in public discussions on the role of the government in tackling obesity ('The government should ... fund campaigns to encourage adults to have a healthier lifestyle/increase taxes on the sale of unhealthy foods/insist that restaurants and takeaways give information on the fat and calorie content on foods/restrict advertising and marketing of unhealthy foods' and 'Weight-loss treatments should be offered free on the NHS'; NHS = National Health Service).

Responses to all questions were on 5-point Likert scales, ranging from 'strongly agree' to 'strongly disagree'.

\section{Statistical analysis}

Analyses were done using the statistical software package IBM SPSS Statistics version 18.0 with weighted data to match the population characteristics. Variables used for weighting included age, sex, social grade and standard region. We repeated the analyses on unweighted data and there were no significant differences in the results, so with the exception of the sample descriptive statistics, only analyses on weighted data are reported.

Descriptive statistics on unweighted data were completed for SES, sex, age, perceived weight status, attributions for overweight and attitudes towards obesity policies. Attributions for overweight and attitudes towards policies were indexed by the proportion of people agreeing or strongly agreeing with each statement, and were also scored as continuous scales from 1 to 5. Repeated-measures ANOVA assessed differences between attributions and between policies. Main effects were decomposed using Bonferroni comparisons. Demographic differences and differences by perceived weight status were examined. Associations between attributions and attitudes were explored using linear regression analyses for each of the five policy statements, controlling for SES, sex and age. In order to take into account multiple comparisons, our level of significance was set at $P<0 \cdot 01$.

\section{Results}

The average age of respondents was $46 \cdot 97$ (SD 19.22) years, with slightly more women than men $(53 \cdot 1 \% v$. 46.9\%). Respondents were distributed across social grade categories: $\mathrm{AB}(15.5 \%, n$ 308); C1 (26.6\%, $n$ 529); C2 (21.3\%, $n$ 424); D (15.8\%, $n$ 314); and $\mathrm{E}(20 \cdot 7 \%, n 411)$.

Only $4 \cdot 8 \%$ ( $n$ 95) of respondents described themselves as 'very underweight' or 'underweight' and only $6 \cdot 1 \%$ ( $n$ 121) described themselves as 'very overweight' or 'obese'. The most widely endorsed option was 'about the right weight' $(52 \cdot 8 \%, n$ 1049), but with a large minority (35.4\%, $n$ 704) describing themselves as 'somewhat overweight'.

\section{Attributions of overweight}

Responses to the general statement on causes of overweight indicated that the majority agreed 'Being overweight is mainly the person's own fault' $(57 \cdot 2 \%)$. However, more respondents agreed that 'People become overweight because there are so many unhealthy foods around' $(61 \cdot 3 \%)$ than 'because they lack will power' (57.0\%), but genetic attributions ('because they inherit genes that cause weight gain') were less frequent (44.6\%); see Table 1. Treating responses as continuous variables confirmed

Table 1 Respondent agreement and mean score with standard deviation for each statement about attributions for overweight and support for obesity policies; population-representative sample of British adults ( $n$ 1986), April 2012

\begin{tabular}{|c|c|c|c|}
\hline & $\begin{array}{l}\text { Agree/strongly } \\
\text { agree }(\%)\end{array}$ & $\begin{array}{l}\text { Mean score } \\
(\text { scored } 1-5)^{*}\end{array}$ & SD \\
\hline \multicolumn{4}{|l|}{ Attributions } \\
\hline People are overweight because they inherit genes that cause weight gain ( $n$ 1926) & $44 \cdot 6$ & $3 \cdot 17$ & 0.96 \\
\hline People are overweight because they lack willpower ( $n$ 1964) & $57 \cdot 0$ & $3 \cdot 43$ & 0.98 \\
\hline People are overweight because there are so many unhealthy foods around ( $n$ 1972) & $61 \cdot 3$ & $3 \cdot 47$ & 1.05 \\
\hline Being overweight is mainly the person's own fault ( $n$ 1973) & $57 \cdot 2$ & $3 \cdot 46$ & 0.98 \\
\hline \multicolumn{4}{|l|}{ Policies for weight management } \\
\hline Weight-loss treatments should be offered free on the NHS ( $n$ 1956) & $48 \cdot 0$ & $3 \cdot 20$ & 1.09 \\
\hline $\begin{array}{l}\text { The government should fund campaigns to encourage adults to have a healthier lifestyle } \\
\text { ( } n \text { 1975) }\end{array}$ & $70 \cdot 8$ & $3 \cdot 65$ & 0.98 \\
\hline The government should increase taxes on the sale of unhealthy foods ( $n$ 1953) & $31 \cdot 5$ & $2 \cdot 72$ & $1 \cdot 14$ \\
\hline $\begin{array}{l}\text { The government should insist that restaurants and takeaways give information on the fat } \\
\text { and calorie content of foods ( } n \text { 1970) }\end{array}$ & $66 \cdot 2$ & 3.58 & 1.07 \\
\hline The government should restrict advertising and marketing of unhealthy foods ( $n$ 1965) & $56 \cdot 5$ & $3 \cdot 36$ & 1.09 \\
\hline
\end{tabular}

NHS, National Health Service.

${ }^{*} A$ higher score reflects a higher level of agreement. 
Table 2 Associations between attributions for overweight and agreement with each obesity policy; population-representative sample of British adults ( $n$ 1986), April 2012

\begin{tabular}{|c|c|c|c|c|c|c|c|c|c|c|}
\hline & \multicolumn{2}{|c|}{$\begin{array}{l}\text { Free weight-loss } \\
\text { treatments }\end{array}$} & \multicolumn{2}{|c|}{$\begin{array}{l}\text { Healthy lifestyle } \\
\text { campaigns }\end{array}$} & \multicolumn{2}{|c|}{$\begin{array}{l}\text { Tax unhealthy } \\
\text { foods }\end{array}$} & \multicolumn{2}{|r|}{$\begin{array}{l}\text { Menu } \\
\text { labelling }\end{array}$} & \multicolumn{2}{|c|}{$\begin{array}{l}\text { Restrict } \\
\text { advertising }\end{array}$} \\
\hline & $\beta$ & $95 \% \mathrm{Cl}$ & $\beta$ & $95 \% \mathrm{Cl}$ & $\beta$ & $95 \% \mathrm{Cl}$ & $\beta$ & $95 \% \mathrm{Cl}$ & $\beta$ & $95 \% \mathrm{Cl}$ \\
\hline Genes & $0 \cdot 12$ & $0 \cdot 08,0 \cdot 18^{*}$ & 0.08 & $0 \cdot 04,0 \cdot 13^{*}$ & 0.04 & $-0.00,0.10$ & 0.04 & $-0.01,0.09$ & 0.03 & $-0.01,0.09$ \\
\hline Willpower & -0.04 & $-0 \cdot 10,0.02$ & 0.01 & $-0.04,0.06$ & 0.03 & $-0.03,0.09$ & 0.04 & $-0.01,0.10$ & 0.06 & $0.04,0.23$ \\
\hline Food environment & $0 \cdot 15$ & $0 \cdot 11,0 \cdot 20^{*}$ & 0.20 & $0 \cdot 14,0.23^{\star}$ & $0 \cdot 26$ & $0.23,0.33^{*}$ & 0.24 & $0 \cdot 19,0.28^{*}$ & 0.28 & $0 \cdot 24,0.33^{*}$ \\
\hline Own fault & $-0 \cdot 10$ & $-0.17,-0.06$ & -0.04 & $-0.09,0.01$ & 0.04 & $-0.01,0.11$ & 0.02 & $-0.03,0.08$ & 0.03 & $-0.03,0.08$ \\
\hline
\end{tabular}

${ }^{*} P<0.001$.

significant differences in attributions for overweight $(F(2 \cdot 68,5407 \cdot 36)=43 \cdot 46, P<0 \cdot 001)$. Respondents agreed significantly less with the statement 'People are overweight because they inherit genes that cause weight gain' than with all three of the other attribution statements (all $P$ values $<0 \cdot 001)$. Agreement that overweight could be attributed to genes was also negatively correlated with the belief that it is the person's own fault $(r=-0 \cdot 17, P<0 \cdot 001)$.

Older people were more likely to agree that people are overweight because of genes $(r=0 \cdot 11, P<0 \cdot 001)$, because there are so many unhealthy foods around $(r=0 \cdot 13, P<0 \cdot 001)$ and because they lack willpower $(r=0 \cdot 10, P<0 \cdot 001)$. Older people were also more likely to agree that 'Being overweight is mainly the person's own fault' ( $r=0 \cdot 07, P=0 \cdot 002)$. There were no gender or SES differences in attributions of overweight. ANCOVA analyses for the attribution statements, controlling for age, gender and SES, showed no significant difference by perceived weight status for any of the four statements (minimum $P$ value $=0 \cdot 07$ ); respondents who perceived themselves as 'somewhat overweight' or 'very overweight/obese' did not have different beliefs about the causes of obesity from respondents who perceived themselves as 'about right' or 'underweight'.

\section{Attitudes towards policies}

Support for the various obesity policies varied (see Table 1), with the highest support for the statement 'The government should fund campaigns to encourage adults to have a healthy lifestyle' $(70 \cdot 8 \%)$. People were least positive about the statement 'The government should increase taxes on the sale of unhealthy foods' (31.5\%). Treating responses as continuous variables confirmed significant differences in attitudes towards the obesity policies $(F(3 \cdot 78,7616 \cdot 59)=$ $304 \cdot 36, P<0 \cdot 001)$. People were significantly less positive towards taxation compared with all of the other policies (all $P$ values $<0 \cdot 001$ ) and were significantly more positive towards healthy lifestyle campaigns and menu labelling than the other policies (all $P$ values $<0 \cdot 001$ ). They were also significantly less positive towards free weight-loss treatments compared with advertising and marketing restrictions $(P<0 \cdot 001)$.

Older people were more likely to agree with the policy statement 'The government should restrict advertising and marketing of unhealthy food' $(r=0 \cdot 10, P<0 \cdot 001)$, but less likely to agree that 'The government should fund campaigns to encourage adults to have a healthier lifestyle' $(r=-0 \cdot 13, P<0 \cdot 001)$ and that 'The government should insist that restaurants and takeaways give information on the fat and calorie content on foods' $(r=-0 \cdot 08, \quad P<0 \cdot 001)$. Men were slightly less likely to agree with the statement 'The government should restrict advertising and marketing of unhealthy foods' $(F(1,1998)=6 \cdot 97, P=0 \cdot 008)$. Respondents in SES group $\mathrm{E}$ were more likely than $\mathrm{AB}, \mathrm{C} 1$ and $\mathrm{C} 2$ respondents to agree that 'Weight-loss treatments should be offered free on the NHS' $(F(4,1995)=6 \cdot 22, P<0 \cdot 001)$. ANCOVA analyses for the policy statements, controlling for age, gender and SES, showed no significant difference by perceived weight status (minimum $P$ value $=0 \cdot 16$ ).

\section{Associations between attributions and attitudes towards obesity policies}

Linear regression analyses for each of the policy statements, controlling for age, sex and SES, were conducted to explore associations with attributions for overweight. All of the models were significant (all $P$ values $<0 \cdot 001$ ), with attributions contributing between $5 \%$ and $9 \%$ of the variance in support for the various policies. Specifically, agreement with 'People are overweight because there are so many unhealthy foods around' was associated with higher support for all of the policies (all $P$ values $<0 \cdot 001$ ); see Table 2. Agreement with 'People are overweight because they inherit genes that cause weight gain' was associated with higher support for weight-loss treatments being provided free on the NHS and government funding of healthy lifestyle campaigns (both $P$ values $<0 \cdot 001$ ); see Table 2 .

\section{Discussion}

In this population-based study of British adults, nearly two-thirds of respondents (57\%) attributed overweight to lack of willpower and $57 \%$ agreed that 'Being overweight is mainly the person's own fault'. Respondents were less likely to attribute overweight to genes ( $45 \%$ ), but the majority (61\%) agreed that the abundance of unhealthy 
foods in our environment is a cause of overweight. This corresponds with previous research in the UK on attributions for overweight and obesity ${ }^{(22,25)}$ and suggests little change as a result of either the public rhetoric on personal responsibility or developments in genetics. While it is reassuring that the majority of participants agree that the food environment is a cause of overweight, the high level of agreement with the statements 'Being overweight is mainly the person's own fault' and 'People are overweight because they lack willpower' suggests that overweight is still associated with considerable stigma in the UK. Given the negative consequences of stigmatizing overweight individuals on both individual well-being and public health $^{(27)}$, it is important to address these attitudes through increasing awareness of the complex aetiology of obesity.

With respect to attitudes towards policies, respondents were most supportive of healthy lifestyle campaigns (71\%) and least positive towards taxation (32\%); similar results to earlier studies indicating that the public favours 'softer' approaches ${ }^{(12-16)}$. However, a high proportion of respondents were also in support of the more regulatory policies: enforced menu labelling (66\%) and advertising restrictions (57\%). Positive shifts in attitudes towards obesity policies have been demonstrated in recent studies from the USA ${ }^{(28)}$ and Germany ${ }^{(29)}$, and our findings suggest that similar changes may be occurring in the UK, which may reflect responsiveness to media reporting of the scale of the public health problem. Public support for a policy was cited by the UK House of Lords ${ }^{(30)}$ as an important indicator of how likely that policy is to succeed. The generally high level of support for the various obesity policies in our study is therefore encouraging and may help to alleviate concern about the introduction of more coercive obesity policies in the UK.

In line with our hypothesis, the belief that overweight is caused either by the food environment or genes was associated with greater support for government policies to prevent and treat obesity, but the effect size was modest. In contrast to previous research, neither the belief that lack of willpower causes overweight nor the belief that overweight is mainly the person's own fault was associated with lower support for any of the policies. It is reassuring to see that personal control attributions did not undermine support for obesity policies. This may reflect increasing awareness that action is needed to combat the obesity epidemic regardless of whether individuals are at fault.

In line with previous studies ${ }^{(13,15,24)}$ some demographic differences were identified, although there was no consistent pattern across all policies. Older age was associated with more support for certain policies, people from lower SES backgrounds were more supportive of free weight-loss treatments, and men were less positive about marketing and advertising restrictions. However, differences were small and the results suggested that broader cultural attitudes hold sway.
While some studies have shown some influence of the person's own weight on attributions or attitudes ${ }^{(15,25,29)}$, others have not ${ }^{(22,28)}$, and we also saw no association. However, a limitation of our study was that it relied on self-reported weight status. The proportion describing themselves as obese or overweight within our sample was well below the proportion of overweight and obese adults seen in the most recent Health Survey for England $(\mathrm{HSE})^{(1)}$, which used measured anthropometric data (53\% in the present survey described themselves as 'about the right weight' $v .37 \%$ normal weight in the HSE, $35 \%$ described themselves as 'somewhat overweight' $v$. $37 \%$ overweight in HSE and just $6 \%$ described themselves as 'very overweight/obese' v. $25 \%$ obese in HSE). It is therefore likely that a large proportion of overweight/ obese respondents were either unaware of their weight status or chose to under-report it, perhaps due to their own feelings of stigmatization. An additional limitation of our study was the use of single-item measures, which are less reliable than multi-item scales.

In our survey, the attribution statements referred to causes of 'overweight' as opposed to 'obesity'. This makes our findings comparable with the previous UK study of the general public's beliefs ${ }^{(22)}$ and is also in line with the majority of the US research on attributions ${ }^{(15,23)}$. However German research in this area has used the term 'obesity'(13,24,29), as did the most recent US study ${ }^{(28)}$. Although findings from these studies are comparable, with attributions typically highest for individual and environmental factors and lowest for genetic factors, there may be subtle differences in the general public's attributions for overweight $v$. obesity, and differences in how these relate to policy attitudes, due to the more negative connotations associated with the term 'obesity' ${ }^{(31)}$. This could be explored in subsequent studies.

In our survey, the policies were described in relatively broad terms. The concept 'healthy lifestyle campaigns' covers a wide range of activities. The public tends to be more positive towards (and motivated by) campaigns that frame their messages around positive health behaviours as opposed to emphasizing the negative aspects of obesity ${ }^{(32)}$. Equally, support for free weight-loss treatments may very much depend on the specific type of treatment being offered. It is also possible that combination policies could attract more support than either alone. For example, a recent review indicated that taxation of high-fat foods and subsidizing fruit and vegetables may be effective in reducing obesity ${ }^{(33)}$; it would therefore be interesting to explore whether support for taxation of unhealthy foods could be increased if it were balanced by subsidies for healthy foods. Future research should consider these nuances.

The results of the present study highlight the potential importance of attributions for overweight in terms of public support for obesity policies and suggest that improving awareness of the multiple causes of obesity could facilitate acceptance of policy action to reduce 
obesity prevalence, and ultimately increase the likelihood of success for these actions.

\section{Acknowledgements}

Sources of funding: This work was supported by Cancer Research UK (grant number C1418/A7974). Conflicts of interest: Both authors declare that they have no conflicts of interest. Authors' contributions: R.J.B. and J.W. conceived the study and developed the questions for the survey. R.J.B. conducted the analyses and drafted the manuscript. J.W. is the grant holder and revised the manuscript.

\section{References}

1. The Health and Social Care Information Centre (2011) Health Survey for England: Adult anthropometric measures, overweight and obesity. https://catalogue.ic.nhs. uk/publications/public-health/surveys/heal-surv-eng-2011/ HSE2011-Ch10-Adult-obesity.pdf (accessed December 2012).

2. McPherson K, Marsh T \& Brown M (2007) Foresight. Tackling Obesities: Future Choices - Modelling Future Trends in Obesity and the Impact on Health. http://www. bis.gov.uk/assets/foresight/docs/obesity/14.pdf (accessed December 2012).

3. Allender S \& Rayner M (2007) The burden of overweight and obesity-related ill health in the UK. Obes Rev 8, 467-473.

4. Visscher TL \& Seidell JC (2001) The public health impact of obesity. Annu Rev Public Health 22, 355-375.

5. Counterweight Project Team (2008) Influence of body mass index on prescribing costs and potential cost savings of a weight management programme in primary care. $J$ Health Serv Res Policy 13, 158-166.

6. House of Commons Health Committee (2004) Obesity. Third Report of Session 2003-04, Volume I. http://www. publications.parliament.uk/pa/cm200304/cmselect/cmhealth/ 23/23.pdf (accessed December 2012).

7. Royal College of Physicians (2004) Storing up Problems. The Medical Case for a Slimmer Nation. Report of a Working Party. London: RCP.

8. Anon (2011) Urgently needed: a framework convention for obesity control. Lancet $\mathbf{3 7 8}, 741$.

9. Department of Health (2010) Healthy Lives, Healthy People: Our Strategy for Public Health in England. Norwich: The Stationery Office.

10. Rayner G \& Lang T (2011) Is nudge an effective public health strategy to tackle obesity? No. BMJ 342, d2177.

11. Anon (2010) The UK Public Health White Paper: 'just words'. Lancet 376, 1959.

12. Branson C, Duffy B, Perry C et al. (2010) Acceptable Behaviour? Public Opinion on Behaviour Change Policy. London: Ipsos MORI.

13. Hilbert A, Rief W \& Braehler E (2007) What determines public support of obesity prevention? J Epidemiol Community Health 61, 585-590.

14. Lund TB, Sandoe P \& Lassen J (2011) Attitudes to publicly funded obesity treatment and prevention. Obesity (Silver Spring) 19, 1580-1585.
15. Oliver JE \& Lee T (2005) Public opinion and the politics of obesity in America. J Health Polit Policy Law 30, 923-954.

16. Morley B, Martin J, Niven VP et al. (2012) Public opinion on food-related obesity prevention policy initiative. Health Promot J Aust 23, 86-91.

17. Sikorski C, Luppa M, Kaiser M et al. (2011) The stigma of obesity in the general public and its implications for public health - a systematic review. BMC Public Health 11, 661.

18. Kim S \& Willis A (2007) Talking about obesity: news framing of who is responsible for causing and fixing the problem. J Health Commun 12, 359-376.

19. De Brun A, McKenzie K, McCarthy M et al. (2011) The emergence and portrayal of obesity in The Irish Times: content analysis of obesity coverage 1997-2009. Health Commun 27, 389-398.

20. Ata RN \& Thompson JK (2010) Weight bias in the media: a review of recent research. Obes Facts 3, 41-46.

21. Heuer C, McClure K \& Puhl RM (2011) Obesity stigma in online news: a visual content analysis. J Health Commun 16, 976-987.

22. Chambers SA \& Traill WB (2011) What the UK public believes causes obesity, and what they want to do about it: a cross-sectional study. J Public Health Policy 32, 430-444.

23. Taylor P, Funk C \& Craighill P (2006). Americans see weight problems everywhere but in the mirror. Pew Research Centre: A Social Trends Report. http://pewresearch.org (accessed December 2012).

24. Hilbert A, Rief W \& Braehler E (2008) Stigmatizing attitudes toward obesity in a representative population-based sample. Obesity (Silver Spring) 16, 1529-1534.

25. Okonkwo O \& While A (2010) University students' views of obesity and weight management strategies. Health Educ J 69, 192-199.

26. National Readership Survey (2007) Lifestyle data. http://www. nrs.co.uk/lifestyle-data/ (accessed December 2012).

27. Puhl R \& Heuer CA (2010) Obesity stigma: important considerations for public health. Am J Public Health 100, 1019-1028.

28. Barry CL, Brescoll VL, Brownell KD et al. (2009) Obesity metaphors: how beliefs about the causes of obesity affect support for public policy. Milbank $Q \mathbf{8 7}, 7-47$.

29. Sikorski C, Luppa M, Schomerus G et al. (2012) Public attitudes towards prevention of obesity. PLoS One 7, e39325.

30. House of Lords Science and Technology Select Committee (2011) Behaviour Change. 2nd Report of Session 2010-12. http://www.publications.parliament.uk/pa/ld201012/ldselect/ ldsctech/179/179.pdf (accessed December 2012).

31. Volger S, Vetter ML, Dougherty M et al. (2012) Patients' preferred terms for describing their excess weight: discussing obesity in clinical practice. Obesity (Silver Spring) 20, 147-150.

32. Puhl R, Peterson JL \& Luedicke J (2013) Fighting obesity or obese persons? Public perceptions of obesity-related health messages. Int J Obes (Lond) 37, 774-782.

33. Powell LM, Chriqui JF, Khan T et al. (2013) Assessing the potential effectiveness of food and beverage taxes and subsidies for improving public health: a systematic review of prices, demand and body weight outcomes. Obes Rev 14, 110-128. 